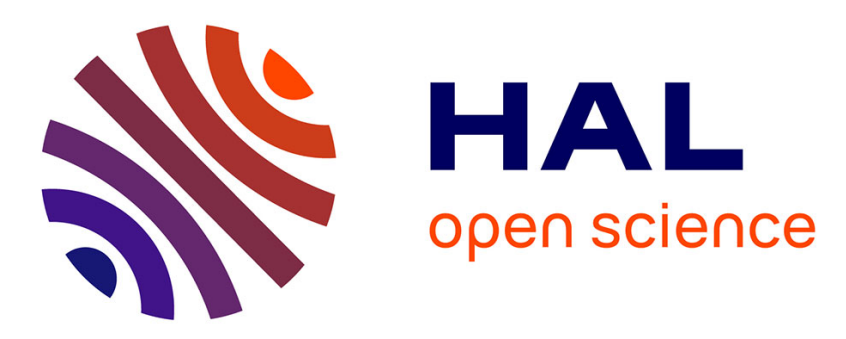

\title{
BiOCl nano/microstructures on substrates: Synthesis and photocatalytic properties
}

Sujuan Wu, Cong Wang, Yinfang Cui, Weichang Hao, Tianmin Wang, Pascal Brault

\section{- To cite this version:}

Sujuan Wu, Cong Wang, Yinfang Cui, Weichang Hao, Tianmin Wang, et al.. BiOCl nano/microstructures on substrates: Synthesis and photocatalytic properties. Materials Letters, 2011, 65, pp.1344-1347. 10.1016/j.matlet.2011.01.078 . hal-00581574

\section{HAL Id: hal-00581574 https://hal.science/hal-00581574}

Submitted on 31 Mar 2011

HAL is a multi-disciplinary open access archive for the deposit and dissemination of scientific research documents, whether they are published or not. The documents may come from teaching and research institutions in France or abroad, or from public or private research centers.
L'archive ouverte pluridisciplinaire HAL, est destinée au dépôt et à la diffusion de documents scientifiques de niveau recherche, publiés ou non, émanant des établissements d'enseignement et de recherche français ou étrangers, des laboratoires publics ou privés. 


\title{
BiOCl nano/microstructures on substrates: synthesis and
}

\author{
photocatalytic properties
}

\author{
Sujuan Wu ${ }^{\text {a }}$, Cong Wang ${ }^{\mathrm{a} *}$, Yinfang Cui ${ }^{\mathrm{a}}$, Weichang Hao ${ }^{\mathrm{a}}$, Tianmin Wang ${ }^{\mathrm{a}}$ \\ Pascal Brault ${ }^{\mathbf{b}}$
}

\begin{abstract}
a. Center for Condensed Matter and Material Physics, Department of Physics, Beihang University, Beijing, 100191, China

b. GREMI, UMR6606 CNRS-Universite d'Orleans BP 6744, 45067 Orleans Cedex 2, France
\end{abstract}

\begin{abstract}
Bismuth oxycholoride $(\mathrm{BiOCl})$ nano/microstructures, including flake and nanowire arrays, were successfully synthesized on Anodic Aluminum Oxide (AAO) templates via sol-gel combined with the vacuum air-extraction method. The flakes are almost vertically aligned on the surface, but nanowire arrays at a lower sol concentration are aligned along the channels. A possible formation mechanism is proposed. Furthermore, the photocatalytic activity of the BiOCl nano/microstructures is investigated by photocatalytic decomposition of Rhodamine $\mathrm{B}(\mathrm{Rh} \mathrm{B})$ dye under UV-Visible light irradiation. Compared with the BiOCl flake film on the glass substrate, where the flakes are horizontally oriented on the surface, the vertically aligned flake and nanowire arrays on AAO templates, have a higher photocatalytic efficiency.
\end{abstract}

\section{Keywords:}

BiOCl; flake film; microstructures; sol-gel preparation.

\section{Introduction}

Recently, Bi-based photocatlytic materials have aroused great interest due to the unique electron structure of $\mathrm{Bi}$, which is beneficial for promoting the mobility of photo-generated carriers $[1,2]$. In particular $\mathrm{BiOCl}$, which has exhibited wide applications as a pigment in the cosmetic industry and as a candidate material for optoelectronic and photovoltaic devices, e.g. 
light-emitting diodes, lasers and solar cells, could perform as an potential excellent photocatalytic material for purifying textile dye polluted wastewater [3]. In 2007, Huang and co-workers firstly reported that $\mathrm{BiOCl}$ exhibited better performance than $\mathrm{TiO}_{2}(\mathrm{P} 25$, Degussa) on the photocatalytic degradation of methyl orange (MO) dye [1]. An [4] and Zhang [5] found that BiOCl exhibited excellent photocatalytic activity on degradation of Rh B and MO dye under both UV and visible light irradiation. Therefore, it is necessary to further investigate $\mathrm{BiOCl}$ growth and morphology to achieve optimum photocatalytic activity and explore the possible applications.

There are two major factors, i.e. high photocatalytic activity and immobilization, that should be considered for the application of photocatalysts [6]. The following strategies can be adopted: phase and morphological control, doping, surface sensitization, composite materials etc. Morphological control of nanostructured materials is one of the efficient and available ways to improve the photocatalytic efficiency due to the high surface-to-volume $(\mathrm{S} / \mathrm{V})$ reachable ratio. Until now, nano-structure materials with different morphologies, such as nanotube, nanowires, flakes, spheres, v-shaped structure, have been fabricated and used to promote the efficiency [7-9]. The second important factor is immobilization. The photocatalyst powders are generally suspended in water, which limits their practical use because of the difficulty in collecting and recycling photocatalyst powders from a suspension. One of the methods to solve this problem is to immobilize the photocatalyst on a substrate, e.g. to form thin films, coatings, or directly control growth of nanostructures on the substrate, to meet the requirements of the future applications.

Although different preparation methods have been reported, the AAO template assisted method is the most widely used and also turns out to be quite efficient [10]. AAO templates can not only control the growth of nanostructure, but also can behave as substrate. Recently, we have prepared the $\mathrm{BiOCl}$ nanowire arrays successfully by employing AAO templates as substrate [11]. Herein, we report the control growth of different morphological BiOCl nano/microstructures on AAO templates and the $\mathrm{BiOCl}$ flake film on glass substrates. Furthermore, their photocatalytic activities were also investigated by photocatalytic decomposition of Rhodamine B (Rh B) dye.

\section{Experiment}

$\mathrm{BiOCl}$ powder was dissolved in $100 \mathrm{ml}$ alcohol to form $0.3 \mathrm{M}, 0.5 \mathrm{M}$ sol, in which $5 \mathrm{M} \mathrm{HCl}$ 
was added to adjust the $\mathrm{pH}=1$ under constant stirring at $60{ }^{\circ} \mathrm{C}$ for $2 \mathrm{~h}$. Then, the commercial AAO template (Whatman company) with a pore diameter of $100 \mathrm{~nm}$ and depth of $60 \mu \mathrm{m}$ was placed in a vessel that contained $2 \mathrm{ml}$ of the prepared $\mathrm{BiOCl}$ sol. After, they were treated under the vacuum air-extraction[12]. The condition of vacuum pressure was $1 \mathrm{~Pa}$ at room temperature for 30 minutes. The resulting samples were collected and dryed at $100^{\circ} \mathrm{C}$ for $10 \mathrm{~h}$. For comparison, the BiOCl flake film on a glass substrate was prepared via the sol-gel dipping method. The glass substrate was dipped slowly into the $0.5 \mathrm{M}$ sol and a raising velocity at $25 \mathrm{~mm} / \mathrm{min}$ was maintained for deposition.

The crystallinity and morphology of the samples was examined by X-ray diffraction (XRD), and field effect-scanning electron microscopy (FE-SEM). Photocatalytic activity of the samples was evaluated by the degradation of $\mathrm{Rh} \mathrm{B}$ dye solution. The samples with the average area of 4 $\mathrm{cm}^{2}$ were put into $20 \mathrm{ml} 0.01 \mathrm{mmol} \mathrm{Rh} \mathrm{B}$ solution, respectively, and kept in darkness for $24 \mathrm{~h}$ to reach the adsorption-desorption equilibrium. The light source was a $35 \mathrm{~W}$ Xe lamp and the distance between the light source and samples was $20 \mathrm{~cm}$. The UV-Visible absorption spectra and diffuse reflectance spectrum were carried out on a Hitachi U-3010 spectrometer.

\section{Results and discussion}

X-ray diffraction (XRD) was used to investigate the phase structures of the samples. All of the sharp diffraction peaks in the XRD patterns were perfectly indexed as pure phase of $\mathrm{BiOCl}$, in good agreement with the standard JCPDS file (No. 06-0249) of BiOCl. A tetragonal lattice with $\mathrm{a}=3.890 \AA$ and $\mathrm{c}=7.369 \AA$ was obatined. The three strongest peaks were indexed as (001), (002) and (003) for the BiOCl flake film on the glass substrate (Figure 1c), whereas (101), (110) and (211) for the $0.5 \mathrm{M}$ sol (Figure 1a) and $0.3 \mathrm{M}$ sol (Figure 1b) on the AAO template. 
Figure 2 displays the SEM images of the $\mathrm{BiOCl}$ morphologies on AAO templates and glass substrates. The flakes, with a diameter of $\sim 3 \mu \mathrm{m}$, thickness of $\sim 300 \mathrm{~nm}$, are densely aligned on the surface of the AAO template (Figure 2a). They are almost perpendicular to the surface. A detailed cross-section image (inset of Figure 2a) shows that the flakes are co-existent with nanowires. By decreasing the concentration of the sol to $0.3 \mathrm{M}$, the flakes disappear and nanowires with the diameter around $100 \mathrm{~nm}$ and length around $3 \mu \mathrm{m}$ are formed (Figure 2b). It can be seen that all nanowires are roughly parallel to each other and vertically oriented on the AAO template to form an array [11]. The morphology of the $\mathrm{BiOCl}$ on glass substrate is different from that on the AAO template. The flakes are parallel to the surface and are stacked layer by layer on the glass substrate. The thickness of these flakes ranges from 50 to $100 \mathrm{~nm}$ with corresponding diameters between 0.5 to $1.5 \mu \mathrm{m}$ (Figure $2 \mathrm{c}$ ). It can be clearly seen that the $\mathrm{BiOCl}$ on the AAO template possesses larger surface-volume area than that on glass.

As a consequence, a possible formation mechanism of different $\mathrm{BiOCl}$ morphologies is proposed (Figure 3). The formation of the flakes can be attributed to the tetragonal matlockite structure of $\mathrm{BiOCl}$ expressed by $\left[\mathrm{M}_{2} \mathrm{O}_{2}\right]\left[\mathrm{Cl}_{\mathrm{m}}\right]$ or $\left[\mathrm{M}_{3} \mathrm{O}_{4+\mathrm{n}}\right]\left[\mathrm{Cl}_{\mathrm{m}}\right](\mathrm{m}=1-3)$, where bismuth oxide based fluorite-like layers, $\left[\mathrm{M}_{2} \mathrm{O}_{2}\right]$ or $\left[\mathrm{M}_{3} \mathrm{O}_{4+\mathrm{n}}\right]$, are intergrown with double chlorine layers $[5,13]$. Hence, the $\mathrm{BiOCl}$ flakes prefer to be formed on the surface of glass and AAO template. During the process of the vacuum air-extraction treatment, these flakes on the template start to stand up and densely packed together. Meanwhile, part of the sol is sucked into the channels and becomes coagulated and solidified in the channels. In the other hand, the concentration of the sol determines its viscosity, which will affect its diffusing ability. The viscosity will decrease correspondingly as the concentration decreases. Therefore, the sol with lower concentration is 
easier to impenetrate into the channels and fully fill them to form nanowire arrays.

The photocatalytic activities of the samples were evaluated for decomposition of Rh B dye. The removal of $\mathrm{Rh} \mathrm{B}$ versus irradiation time is plotted in Figure 4a. The initial data shows the normalized concentration after $24 \mathrm{~h}$ equilibration of adsorption-desorption. Remarkably, $\sim 39 \%$ and $\sim 42 \%$ of the initial dye is removed from the aqueous solution by adsorption on the BiOCl flakes and nanowire arrays on $\mathrm{AAO}$ templates, respectively. The $\mathrm{BiOCl}$ on glass substrate removes only $\sim 3 \%$ of the dye. The photocatalytic reaction is simply described by

$$
-\mathrm{d}[\mathrm{c}] / \mathrm{dt}=\mathrm{k}[\mathrm{c}],
$$

where $[\mathrm{c}]$ is the $\mathrm{Rh} \mathrm{B}$ concentration, and $\mathrm{k}$ being the degradation rate constant. The calculated degradation rate constants in decomposing $\mathrm{Rh} \mathrm{B}$ with photocatalytic samples is shown in Figure 4b., and is found to dramatically increase from $0.0038 \mathrm{~min}^{-1}$ for the horizontally oriented flakes film, to $0.0067 \mathrm{~min}^{-1}$ for the nanowire arrays and $0.0242 \mathrm{~min}^{-1}$ for the vertically aligned flakes. The BiOCl nanowire arrays and the vertically aligned flakes on the AAO template exhibit high photocatalytic activities, whereas the horizontally oriented $\mathrm{BiOCl}$ flakes on the glass substrate show a lower efficiency. As indicated in the Figure 4a, the bare AAO template can not cause any adsorption and degradation of the dye. Hence, the higher adsorption and efficiency of the BiOCl on the AAO templates can be attributed to the special morphology of $\mathrm{BiOCl}$ structures.

\section{Conclusion}

The vertically aligned flakes, nanowire arrays on AAO templates, and horizontally oriented flakes on glass substrates have been successfully formed. It is found that the concentration of the sol has a strong impact on the morphologies of the BiOCl nanostructures on AAO templates. Specifically, nanowire arrays are prepared at a concentration of the sol is $0.3 \mathrm{M}$, whereas vertically aligned 
flakes are formed on surface at a concentration of $0.5 \mathrm{M}$. The photocatalytic action has been evaluated by degradation of $\mathrm{Rh} \mathrm{B}$ dye under $\mathrm{UV}$-visible light. We find that $\mathrm{BiOCl}$ nano/micro structures on AAO templates possesses higher photocatalytic efficiency than the $\mathrm{BiOCl}$ on glass substrates. This efficiency can be dramatically improved by controlling the morphology.

\section{Acknowledgements}

This project was financially supported by the National Basic Research Program of China under grant number 2007CB613302 and the National Natural Science Foundation of China (NSFC) (No.

50772008, No.50732004).

\section{References}

[1] Zhang KL, Liu CM, Huang FQ, Zheng C, Wang WD. Appl Catal B 2006; 68: 125-9.

[2] He C, Gu M. Scripta Mater 2006; 54:1221-5.

[3] Deng ZT, Tang FQ, Muscat AJ. Nanotechnology 2008;19: 295705-1-6 (6pp).

[4] An HZ, Du Y, Wang TM, Wang C, Hao WC, Zhang JY. Rare Met 2008; 27:243-50.

[5] Zhang X, Ai ZH, Jia FL, and Zhang LZ. J Phys Chem C 2008; 112: 747-53.

[6] Jung HS, Hong YJ, Li Y, Cho J, Kim Y, Yi G. ACS Nano 2008; 4: 637-42.

[7] Bae J, Han JB, Zhang XM, Wei M, Duan X, Wang ZL, et al. J Phys Chem C 2009; 113: 10379-83.

[8] Wang G, Lu W, Li JH, Choi JY, Jeong Y, J. B. Park, et al. Small 2006; 12: 1436-9.

[9] Tang QW, Sun XM, Li QH, Wu JH, Lin JM, Huang ML. Mater Lett 2009; 63: 540-2.

[10] Wang Q, Sun X, Luo SJ, Sun LN, Wu XL, Cao M, Hu C. Cryst Growth Des 2007; 7: 2665-9.

[11] Wu SJ, Wang C, Cui YF, Wang TM , Huang BB, Brault P, et al. Mater Lett 2010; 64: 115-8.

[12] Wang GJ, Lin YC, Li CW, Hsueh CC, Hsu SH, Hung HS. Biomed Microdevices 2009; 11: 843-50.

[13] Lei YQ, Wang GH, Song SY, Fan WQ, Zhang HJ. Cryst Eng Comm 2009; 11: 1857-62.

\section{Figure captions}

Fig 1. XRD patterns of the $0.5 \mathrm{M}$ sol on AAO template (a); $0.3 \mathrm{M}$ sol on AAO templates (b); and the BiOCl film on glass substrates (c).

Fig 2. The SEM images of BiOCl flakes structure, from $0.5 \mathrm{M}$ sol (a) and nanowire array structures, from 0.3 M sol (b) on AAO templates, and BiOCl film on glass substrates (c).

Fig 3. Schemetic illustration of the formation mechanism of $\mathrm{BiOCl}$ nano/micro structures on $\mathrm{AAO}$ templates.

Fig 4. First order plots for the photocatalytic degradation of Rh B (a) and the corresponding degradation rate constants (b) for flakes, nanowire arrays, and film on glass substrate. 


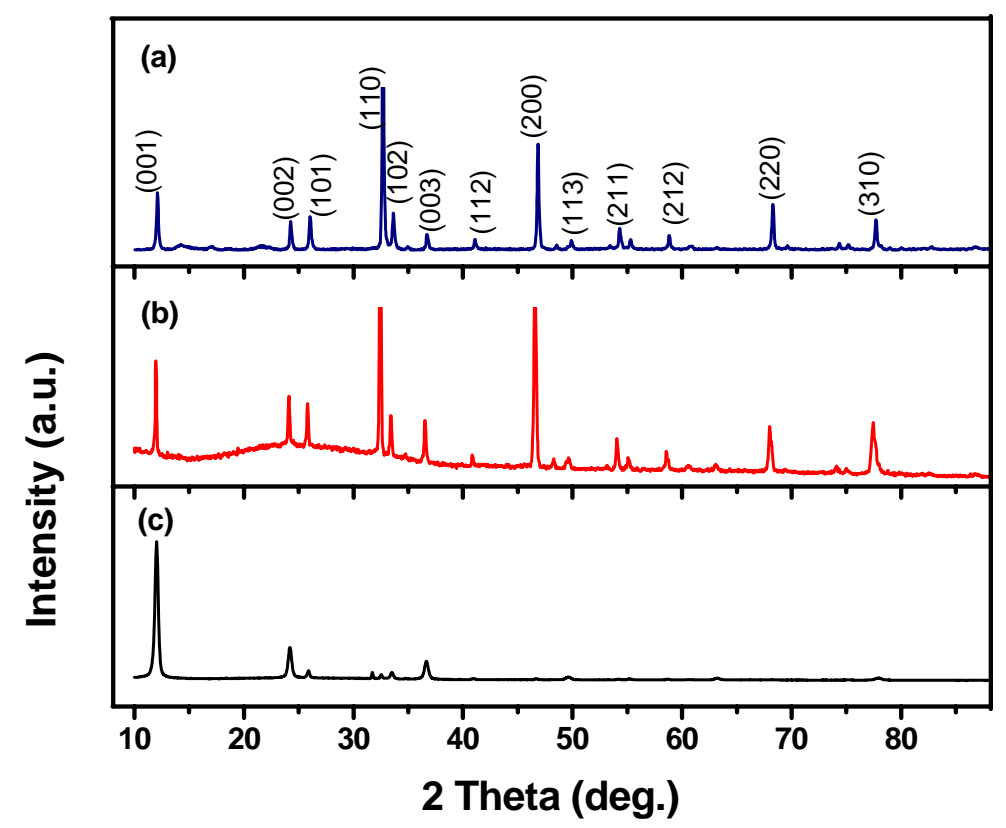

Fig 1

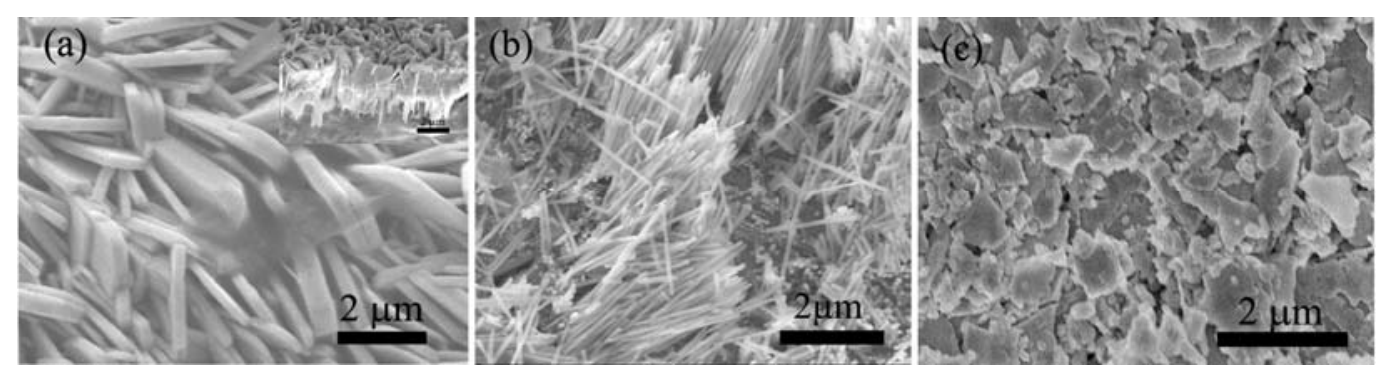

Fig2 


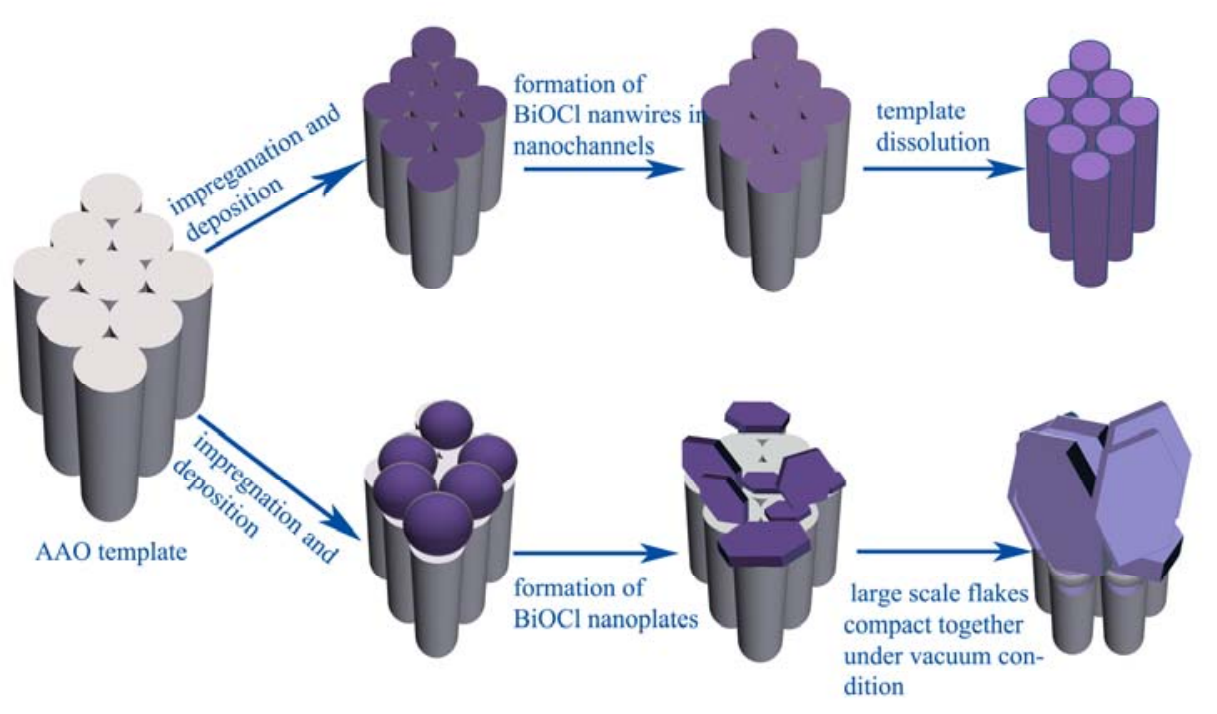

Fig 3
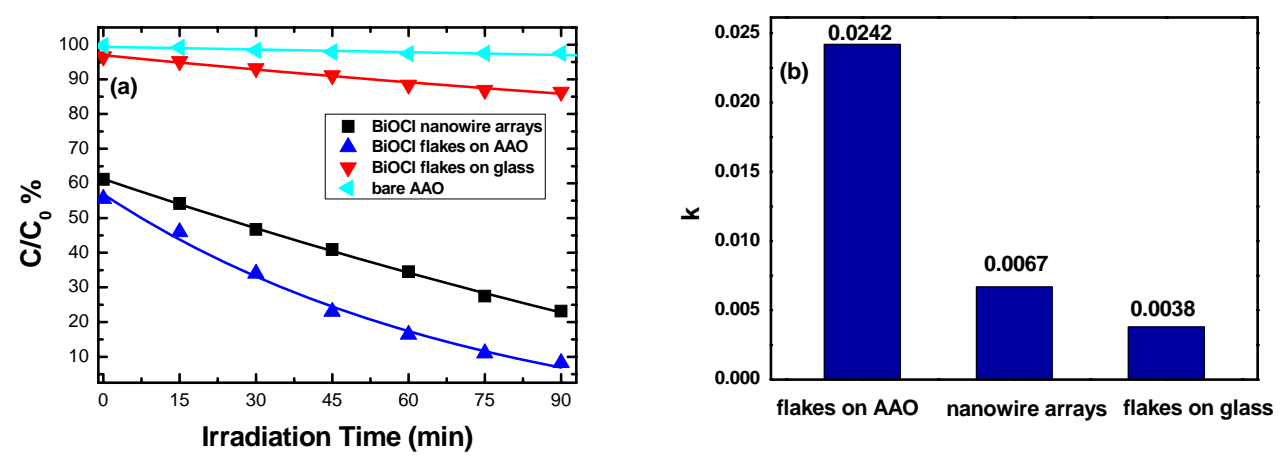

Fig 4 